\title{
Generalist versus specialist: the performances of perch and ruffe in a lake of low productivity
}

Schleuter D, Eckmann R. Generalist versus specialist: the performances of perch and ruffe in a lake of low productivity.

Ecology of Freshwater Fish 2008: 17: 86-99. (c) 2007 The Authors. Journal compilation @ 2007 Blackwell Munksgaard

Abstract - To elucidate the performances of perch and ruffe in oligotrophic lakes, we carried out a field study in reoligotrophic Upper Lake Constance. Both these percids used the same habitat, albeit with different activity patterns. Interspecific competition for food was relevant only in summer when both species fed on zoobenthos. Even then, niche overlap was low, while intraspecific diet overlap was moderate to high throughout the season. Perch did not perform fixed, ontogenetic diet shifts, but used a wide range of prey. During spring and early summer, all size classes were planktivorous, then switched to benthivory and cannibalism in summer, and part of the population reverted to planktivory in autumn. Ruffe, by contrast, fed mainly on chironomid larvae and pupae throughout the year. It is suggested that in lakes of low productivity the euryphagous characteristics of perch, including cannibalism, provide a clear advantage over the benthivorous specialist ruffe in two ways: (i) it allows perch to switch to alternative prey types if one prey type becomes scarce; and (ii) reduces both intra- and interspecific competition for food.

\section{Schleuter, R. Eckmann}

Limnological Institute, University of Konstanz, Konstanz, Germany

Key words: diet overlap; ontogentic diet shift; competition; Perca fluviatilis; Gymnocephalus cernuus

D. Schleuter, Limnological Institute, University of Konstanz, 78457 Konstanz, Germany; e-mail: dianaschleuter@web.de

\section{Introduction}

The species composition of fish communities in temperate lakes of the northern hemisphere, and the relative proportions of different trophic guilds in the total fish biomass, change in a predictable way along a productivity gradient (Persson et al. 1991; Jeppesen et al. 2000, 2005; Olin et al. 2002). Piscivorous species contribute more to the total fish biomass in oligotrophic lakes, while planktivorous species dominate the fish community under eutrophic conditions (Jeppesen et al. 2000, 2005), resulting in a succession from salmonids to percids to cyprinids with increasing productivity (Persson et al. 1991). Within these taxonomic groups, however, the performance of certain species may differ in response to particular environmental conditions. Among the percids, for example, perch (Perca fluviatilis L.) and ruffe (Gymnocephalus cernuus (L.)) respond differently to increasing productivity. Perch attain the highest population biomass under mesotrophic conditions, while ruffe prosper under mesotrophic to eutrophic conditions (Bergman 1991; Jeppesen et al. 2000; Olin et al. 2002).
As perch and ruffe are potential competitors for benthic food resources (Bergman \& Greenberg 1994; Fullerton et al. 2000; Dieterich et al. 2004; Schleuter \& Eckmann 2006), the dominance of one percid species over the other is probably due to its competitive advantage at a certain level of lake productivity. Perch, as a visually oriented predator, thrives best under well-lit mesotrophic conditions, but its foraging efficiency is severely reduced under turbid or dimly-lit conditions (Diehl 1988; Radke \& Gaupisch 2005). Ruffe, by contrast, may forage efficiently under these latter conditions due to its very sensitive lateral line system and the light-reflecting tapetum lucidum in its eye (Collette et al. 1977; Janssen 1997).

Empirical evidence for this concept came from a comparison by Bergman (1991) of perch and ruffe abundances among Swedish lakes of different productivity. She suggested that higher turbidity in the more productive lakes restricted the habitats available for perch and thus decreased their competitive success. Apart from these productivity-related differences in the abundances of perch and ruffe among lakes, a niche divergence within lakes was also attributed to 
the species' sensory abilities, with perch occurring in well-lit, shallow habitats and ruffe in darker, deeper parts of a lake (Bergman 1988).

The succession from perch to ruffe with increasing lake productivity is thus well documented, and the mechanistic explanation for this pattern, based on foraging efficiency, is well established. The low abundances of ruffe in oligotrophic lakes, however, have received less attention so far, and a mechanistic understanding of why ruffe abundances are low in these lakes is missing. Although it is obvious that the superior performance of ruffe under turbid and dark conditions does not convey any advantage over perch in nutrient-poor, and hence clear and well-lit lakes, this is not a sufficient explanation for the succession from ruffe to perch with decreasing lake productivity. To elucidate the factors that might contribute to lower ruffe abundances in oligotrophic lakes, we studied the performances of perch and ruffe in Upper Lake Constance (ULC), a large lake that has recently returned to oligotrophic conditions.

Ruffe was accidentally introduced into Lake Constance (Fig. 1) in the 1980s, where it rapidly established large populations despite the lake's ongoing reoligotrophication (Rösch \& Schmid 1996). In warm monomictic ULC, the total phosphorous concentration measured during turnover in late winter $\left(\mathrm{TP}_{\text {mix }}\right)$ had increased from the mid-1950s $\left(\mathrm{TP}_{\text {mix }}<5 \mu \mathrm{g} \cdot \mathrm{L}^{-1}\right)$ to the late $1970 \mathrm{~s}\left(\mathrm{TP}_{\text {mix }}>80 \mu \mathrm{g}\right.$. $\left.\mathrm{L}^{-1}\right)$ as a result of anthropogenic eutrophication. This trend was reversed through the installation of sewage treatment plants and the ban on phosphorous-containing detergents, leading to continuously decreasing nutrient loads during the 1980s and 1990s, and consequently a return to oligotrophy $\left(\mathrm{TP}_{\text {mix }}=7 \mu \mathrm{g}\right.$. $\mathrm{L}^{-1}$ in 2006). When ruffe became established in ULC in the late 1980s, the lake was still considered to be mesotrophic, and ruffe became one of the most abundant species in the littoral zone by the mid1990s (Fischer \& Eckmann 1997; Eckmann \& Rösch 1998). The increase in ruffe population size coincided with a decrease in the growth rate of perch, the second most important commercial fish species in ULC (Eckmann \& Rösch 1998; Eckmann et al. 2006); and stakeholders feared a negative impact of ruffe on perch (Eckmann \& Rösch 1998; Eckmann et al. 2006). Recent observations, however, indicate that the population of ruffe is declining (Reyjol et al. 2005).

During the eutrophication of Lake Constance, perch became more limnetic and deviated from their typical ontogenetic diet shift, i.e., from planktivory through benthivory to piscivory in oligotrophic Lake Constance in the 1930s (Nümann 1939), until, in the 1980 s, all size classes of perch fed almost exclusively on zooplankton throughout the year (Hartmann 1975; Hartmann \& Nümann 1977; Eckmann et al. 2006). Hence, when ruffe became established in ULC, competition with perch for benthic resources was unimportant, and Schmid (1999) concluded that ruffe had occupied an 'empty niche' in ULC. With ongoing reoligotrophication and decreasing zooplankton abundance, however, perch recently started to include

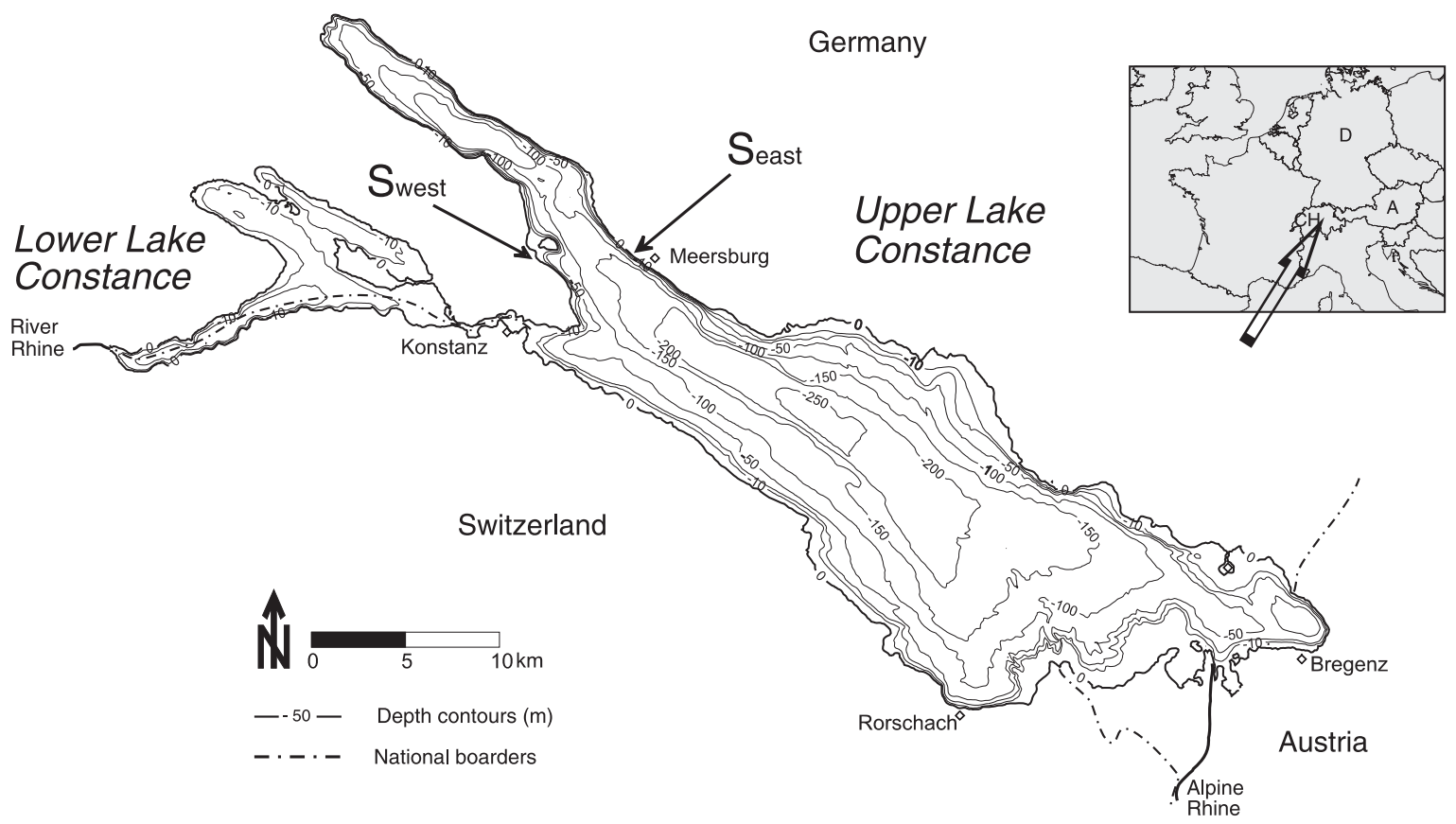

Fig. 1. Lake Constance at the borders between Austria, Germany and Switzerland. The study sites are located in the western part of Upper Lake Constance. 
benthos in their diet again, so that competition for food with ruffe might start to take effect. The increasing potential for interspecific competition for food between perch and ruffe thus provided a unique opportunity to compare the performances of these two percids in a lake that is gradually advancing towards the lower end of the productivity gradient.

The aim of this study was, therefore, to compare the effects of reoligotrophication on the foraging performances of, and the competitive interactions between, the two percids perch and ruffe, focussing on the question of which factors may cause the low abundances of ruffe relative to perch under oligotrophic conditions. We carried out fishing surveys in combination with line transect scuba diving and focussed especially on depth distributions, diurnal migration patterns and diet compositions of both species. To account for the possible seasonal patterns in these variables, sampling was performed monthly during the growing season of 2004, when both species occur in the littoral zone.

\section{Methods}

Study sites

Upper Lake Constance is a large $\left(473 \mathrm{~km}^{2}\right)$, deep $\left(z_{\max }=254 \mathrm{~m}, z_{\text {mean }}=101 \mathrm{~m}\right)$, prealpine lake in Central Europe (Fig. 1). The shoreline is $186 \mathrm{~km}$ long, and the littoral zone (from the shoreline to $10-\mathrm{m}$ depth) comprises about $10 \%$ of the lake area. Down to a depth of 2.5-3 m, the bottom has a more or less gentle slope, depending on the site, while the slope increases at greater depth. Water level fluctuates by about $1.5 \mathrm{~m}$ from the lowest level in February to the highest in summer. The main wind direction is from the west throughout the year, but during winter strong north-easterly winds may also occur.

Because littoral width and slope, sediment composition and wind exposure vary greatly along the shoreline, we chose two study sites on opposite shores with contrasting abiotic conditions (Fig. 1). Site $\mathrm{S}_{\text {west }}$ $\left(47^{\circ} 41^{\prime} 26.67^{\prime \prime} \mathrm{N}, 9^{\circ} 12^{\prime} 18.36^{\prime \prime} \mathrm{E}\right)$ is characterised by low wind exposure, a broad, gently sloping littoral zone, and heterogeneous substratum with a high fraction of fine sediment. Site $\mathrm{S}_{\text {east }}\left(47^{\circ} 41^{\prime} 37.25^{\prime \prime} \mathrm{N}\right.$, $9^{\circ} 16^{\prime} 11.66^{\prime \prime} \mathrm{E}$ ), by contrast, is more exposed to the prevailing westerly winds, the littoral zone is narrow with a steep slope, and the substratum is more homogeneous, consisting mainly of coarse stones. The benthic communities differ between the two sites, with higher total macrozoobenthos abundance and higher proportions of chironomids, trichopterans and ephemeropterans at the more exposed site $S_{\text {east }}$ (Scheifhacken 2006; D. Schleuter \& N. Scheifhacken, unpublished data).

\section{Fish sampling}

Fish were sampled from both sites at the beginning of each month from May to October 2004. Two bottom gill nets (1.6 m deep, $20 \mathrm{~m}$ long, mesh sizes $6,9,12$, $15,20 \mathrm{~mm}$ bar mesh) were set parallel to the shoreline at $2.5-$ and $10-\mathrm{m}$ depths, respectively. To monitor diurnal changes of fish depth distribution and feeding activity, both nets were exposed three times on each sampling date for $1.5 \mathrm{~h}$ during the dawn, day and dusk. A third gill net (1.6 m deep, $10 \mathrm{~m}$ long, mesh sizes as before) was exposed perpendicular to the shoreline at less than 2-m depth from August to October at $S_{\text {west }}$ and in September and October at $S_{\text {east }}$. Further, samples were taken at $S_{\text {west }}$ in August and October 2003, and at both sites in September 2005. Additional perch stomach samples were obtained during fishing campaigns in June and August 2006. Water temperature at $1-\mathrm{m}$ water depth and Secchi depth were measured on each sampling date. Fish were removed from the nets immediately after they were lifted and transferred to a lethal dose of $1,1,1$ trichloro-2-methyl-2-propanol-hemihydrate $\left(2 \mathrm{~g} \cdot \mathrm{L}^{-1}\right)$. Formalin $(10 \%)$ was injected into the body cavity and the fish were stored in $4 \%$ formalin for later processing.

\section{Zooplankton}

Zooplankton was sampled in 2004 at both sites during the day and after sunset. Triplicate samples from the upper $10 \mathrm{~m}$ of water were collected with an Apstein net (mesh size $100 \mu \mathrm{m}$ ) and preserved in 4\% sugar formalin. Each sample was quantitatively flushed into a counting chamber, identified to species level and counted. Copepods and daphnids were grouped into two size classes, $\leq 0.8$ and $>0.8 \mathrm{~mm}$ for copepods, and $\leq 1.6$ and $>1.6 \mathrm{~mm}$ for daphnids, excluding setae and caudal spines, respectively. Total zooplankton abundances were similar between replicates, with a mean coefficient of variation of 0.15 (range 0.02-0.30). Therefore, data for each sampling site were averaged across the replicates and pooled over sampling time.

\section{Fish catch per unit effort}

In the laboratory, fish were measured and weighed to the nearest $0.1 \mathrm{~cm}$ and $0.1 \mathrm{~g}$, respectively. Perch were divided into three size classes: $\mathrm{P}_{1}: \leq 9.5 \mathrm{~cm}$ (maximum total length of $0+$ perch in ULC at the end of the year), $\mathrm{P}_{2}: \quad 9.5<\mathrm{TL} \leq 13.0 \mathrm{~cm} \quad(13.0 \mathrm{~cm}$ maximum total length of $1+$ perch), $\mathrm{P}_{3}:>13.0 \mathrm{~cm}$. Ruffe were divided into two size classes: $\mathrm{R}_{1}: \leq 9.0 \mathrm{~cm}$ (maximum total length of $0+$ ruffe in ULC at the end of the year) and $\mathrm{R}_{2}:>9.0 \mathrm{~cm}$. 
The gill net catches were standardised by calculating the catch per unit effort (CPUE) as:

$$
\mathrm{CPUE}=\frac{\left(A_{\mathrm{s}} / A_{\mathrm{u}}\right) C_{\mathrm{a}}}{t}
$$

where $A_{\mathrm{s}}$ is the area of standard net $\left(15 \mathrm{~m}^{2}\right.$ : area of the smallest net used), $A_{\mathrm{u}}$ is the area of the net used $\left(\mathrm{m}^{2}\right)$, $C_{\mathrm{a}}$ is the actual catch and $t$ is the fishing time (h).

\section{Depth distribution and activity}

Depth distributions of the fish were described separately for the different fishing times (dawn, day and dusk) by the relative proportion of CPUE from the gill nets set at 2.5- and 10-m depth. Because perch are inactive during darkness and can therefore not be caught by gill nets during the night, depth distributions of fish during the night were analysed based on line transect scuba diving surveys. These surveys were carried out monthly during the day and at night as an alternative method to determine fish distribution. At both sites three parallel ropes were anchored with pegs perpendicular to the shoreline from $10-\mathrm{m}$ to about $0.5-\mathrm{m}$ water depth. The ropes were divided into $10-\mathrm{m}$ sections by numbered marks. As the inclination of the shore is steeper at $S_{\text {east }}$, this resulted in five sections at $\mathrm{S}_{\text {east }}$ and seven sections at $\mathrm{S}_{\mathrm{west}}$. During the day and after sunset, a scuba diver swam slowly along each rope, always starting at 10-m depth, counting all fish along each $10-\mathrm{m}$ section that stayed within $50 \mathrm{~cm}$ on both sides of the rope. When fish abundance was too high to be counted ( $N=50$ or higher), it was estimated. For a data analysis, fish were separated into those occurring at shallow depth $(<2.5-\mathrm{m}$ water depth: five transects at $S_{\text {west }}$, two transects at $S_{\text {east }}$ ) and those occurring at greater depth $(>2.5-\mathrm{m}$ water depth: two transects at $\mathrm{S}_{\text {west }}$, three transects at $\mathrm{S}_{\text {east }}$ ). Fish counted per transect were averaged over the three parallel ropes at each site. Fish density in shallow water and at greater depth was then calculated by weighting the fish counts in the shallow and the greater depth by the number of transects surveyed in these depth strata $\left(\mathrm{N}\right.$ fish $10 \mathrm{~m}^{-1}$ ). Because absolute numbers of fish counted cannot be compared directly with CPUE from gill nets, relative proportions of fish in shallow and deep water are used in Fig. 5 to compare fish distributions obtained by both methods.

\section{Diet analysis}

Stomachs of perch and ruffe were removed, and stomach fullness was assigned to one of three levels: $0=$ empty, $1=$ medium filled (prey items present, but stomach wall not stretched), $2=$ stomach full. Prey items were identified to the family, genus or species level. Copepods and daphnids were grouped into size classes as described in the section on zooplankton. Amphipods were grouped into three size classes (Gammarus roeseli: small $\leq 4 \mathrm{~mm}, 4<$ medium $<12 \mathrm{~mm}$, large $\geq 12 \mathrm{~mm}$; Dikerogammarus villosus: $\quad$ small $\leq 6 \mathrm{~mm}, \quad 6<$ medium $<16 \mathrm{~mm}$, large $\geq 16 \mathrm{~mm}$ ). For all other prey, mean lengths were determined. Dry mass of prey organisms was estimated using length:dry mass regressions for zooplankton from Eckmann et al. (2002) and Laude (2002), and for macrozoobenthos from Baumgärtner \& Rothhaupt (2003) and D. Schleuter \& N. Scheifhacken (unpublished data). For prey fish, the mean length of $0+$ perch (the most common prey fish) of each monthly catch was determined and converted into dry mass after Hanson et al. (1997).

The stomach content percentage composition by biomass was determined for each size class of perch and ruffe for each sampling date and site. A fish size class was classified as planktivorous, benthivorous or piscivorous if more than $50 \%$ of the stomach content dry mass fell into one of these prey categories. When this criterion was not met, a fish size class was assigned to the two trophic guilds which contributed most to the stomach content dry mass. The average dry mass of each type of prey consumed (51 different prey types were considered) was calculated separately for each size class of perch and ruffe for each sampling date and site.

Based on these data, intra- and interspecific diet overlap among the different size classes (perch: $\mathrm{P}_{1}-\mathrm{P}_{2}$, $\mathrm{P}_{2}-\mathrm{P}_{3}, \mathrm{P}_{1}-\mathrm{P}_{3}$; ruffe: $\mathrm{R}_{1}-\mathrm{R}_{2}$; perch-ruffe: $\mathrm{P}_{1}-\mathrm{R}_{1}$, $\mathrm{P}_{2}-\mathrm{R}_{1}, \mathrm{P}_{3}-\mathrm{R}_{1}, \mathrm{P}_{1}-\mathrm{R}_{2}, \mathrm{P}_{2}-\mathrm{R}_{2}, \mathrm{P}_{3}-\mathrm{R}_{2}$ ) was calculated following Schoener (1971):

$$
C x y=1-0.5\left(\sum p_{x m i}-p_{y n i}\right)
$$

where $C$ is the overlap index ranging from 0 (no overlap) to 1 (complete overlap), $p_{x m i}$ is the proportion of food type $i$ used by size class $m$ of species $x$ and $p_{y n i}$ is the proportion of food type $i$ used by size class $n$ of species $y$. Index values $<0.05$ were considered as zero, values from 0.05 to $<0.25$ as low, values from 0.25 to $<0.5$ as medium, and values $\geq 0.5$ as high diet overlap, and the relative frequencies of the different index levels were calculated.

To evaluate intraspecific diet overlap and individual dietary differences within each size class of each species, up to 10 individuals (minimum four individuals) per size class were randomly selected from the August and September samples from both study sites. Fish were chosen from those sampling times, when they were expected to have the fullest stomachs, resulting in perch being selected from the samples taken during the day and at dusk, and ruffe being selected from samples taken during the dawn. Diet overlaps were then calculated for all possible combinations of two of four to 10 individuals, resulting in 
six to 45 overlap values. All data were pooled over sampling date and site. Low and medium index values for individual intraspecific diet overlaps were pooled as medium for further analyses.

The selectivity of perch for zooplankton was calculated according to Strauss (1979):

$$
L=d_{i}-e_{i}
$$

where $d_{i}$ is the proportion of prey type $i$ in the fish diet and $e_{i}$ is the proportion of prey type $i$ in the environment. $L$ ranges from -1 to +1 , with $L=0$ indicating unselective feeding, while negative/positive values indicate that a prey type occurs less/more often in the diet than expected under random feeding. Index values $<0.25$ were considered as low, values from 0.25 to $<0.5$ as medium, and values $\geq 0.5$ as strong prey selection.

\section{Results}

Temperature, Secchi depth, zooplankton

During the sampling period in 2004, temperature, Secchi depth and zooplankton abundance showed the typical seasonal pattern of lakes in the northern temperate zone (Fig. 2). Temperatures were around $10{ }^{\circ} \mathrm{C}$ in May and peaked in August at around $23{ }^{\circ} \mathrm{C}$. A clear water phase occurred in June, the time when daphnids were most abundant, with Secchi depths of $9.7 \mathrm{~m}$ at $\mathrm{S}_{\text {west }}$ and $7.7 \mathrm{~m}$ at $\mathrm{S}_{\text {east }}$. Secchi depth was the lowest $\left(3.0 \mathrm{~m}\right.$ at $\mathrm{S}_{\mathrm{west}}$ and $3.5 \mathrm{~m}$ at $\left.\mathrm{S}_{\text {east }}\right)$ in August, after zooplankton abundance had decreased strongly during July. In August, zooplankton abundance was low at $\mathrm{S}_{\text {west }}$, while it was higher at $\mathrm{S}_{\text {east }}$ due to the predacious cladoceran Leptodora kindtii. A second peak of Secchi depth (about $7.0 \mathrm{~m}$ at both sites) and of daphnid abundance occurred in September. Secchi depth increased marginally in October, while zooplankton abundance decreased towards the end of the growing season.

\section{Fish distribution}

At both sites perch was the most abundant species and contributed around $70 \%$ to the total catch (Fig. 3a,b). The relative abundance of ruffe was slightly higher at $\mathrm{S}_{\text {east, }}$ while the relative abundance of cyprinids (mainly dace Leuciscus leuciscus (L.) and bleak Alburnus alburnus (L.)) was higher at $\mathrm{S}_{\text {west }}$. The relative abundances of perch and ruffe based on counts by the scuba divers, by contrast, did not differ between sites. Gill net catches and the total numbers of fish counted by the scuba divers were higher at $\mathrm{S}_{\text {east }}$ than at S west. $_{\text {Din }}$

During 2004, a pronounced seasonal pattern was apparent in the abundance of perch (Fig. 4). As the
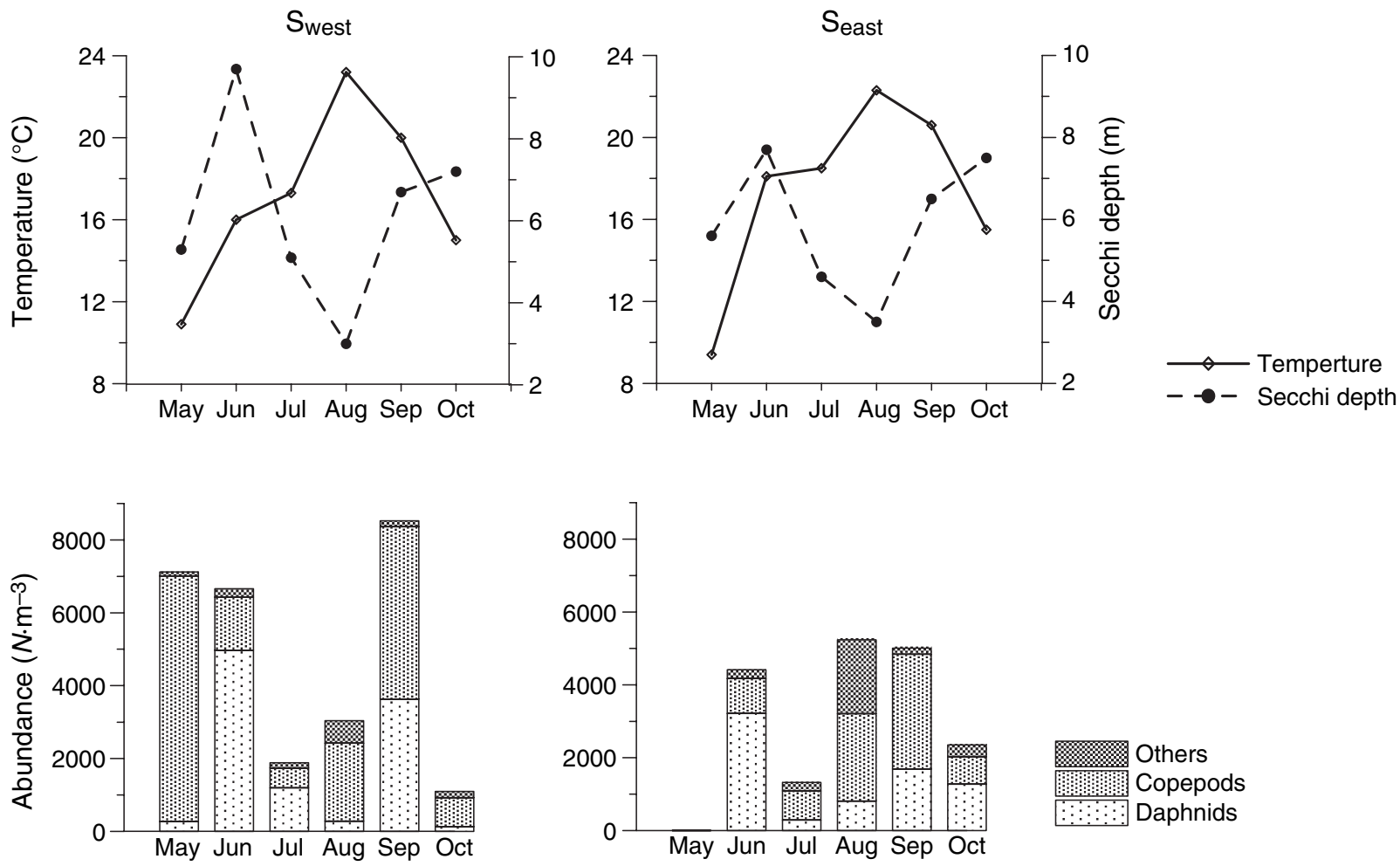

Fig. 2. Temperature and Secchi depth (upper panels) and plankton abundance (lower panels) at the two study sites during the growing season 2004. Others: Bythotrephes longimanus, Leptodora kindtii and Bosmina spp. 
(a)

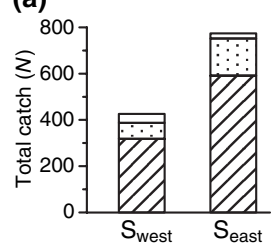

(b)

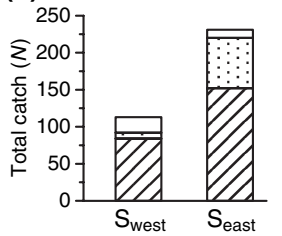

(c)

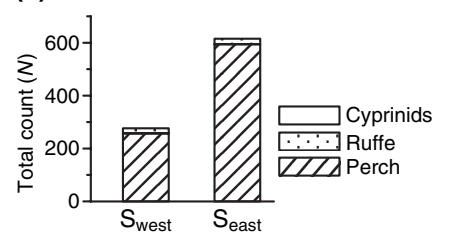

Fig. 3. Total numbers of fish caught with bottom gill nets exposed at $2.5-\mathrm{m}$ and $10-\mathrm{m}$ water depth at the two study sites in Lake Constance (a) from May to October 2004; and (b) in September 2005; (c) total numbers of fish counted by scuba divers (averaged over the three transect lines ranging from 10- to $0.5-\mathrm{m}$ water depth) at the two study sites from May to October 2004.

Perch

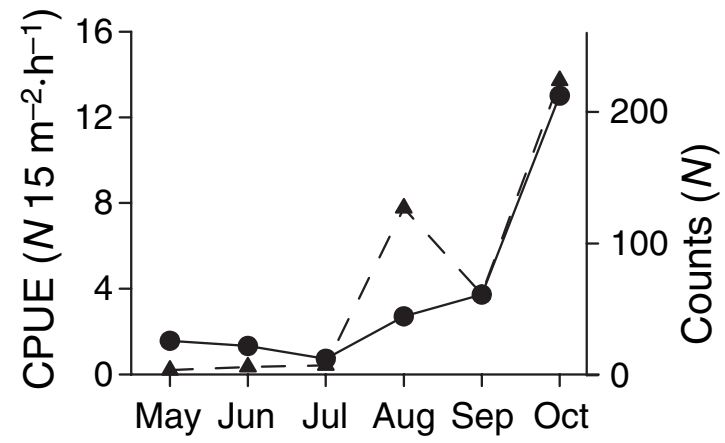

$\longrightarrow$ CPUE gill nets

- ᄂ - Diver counts per $70 \mathrm{~m}$
Ruffe

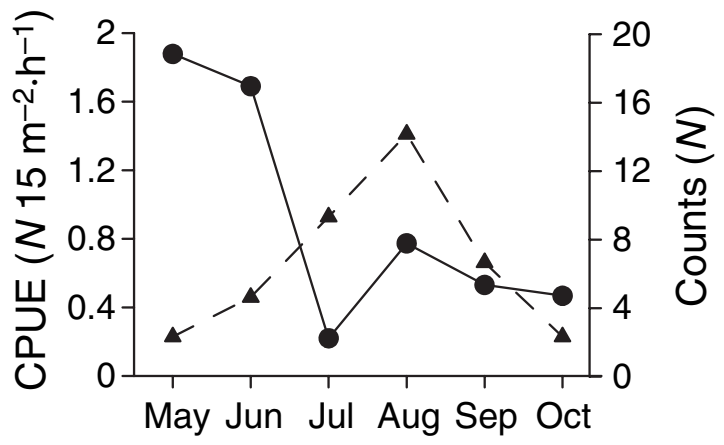

Fig. 4. Mean CPUE and mean numbers of fish counted by scuba divers during 2004 in Lake Constance for perch and ruffe. Data from both sampling sites were pooled.

patterns were very similar at both sites, the data were pooled, but the gill net set at less than 2-m water depth was not included, as it was only used during the second half of the season. During the first half of the season (May-July), perch abundances were very low. During the second half of the season (August-October) CPUEs and diver counts increased until October. This increase was mainly due to the appearance of youngof-the-year (y-o-y) perch, which returned to the littoral zone after the completion of their obligate pelagic phase. In the case of ruffe, by contrast, no consistent pattern in its abundance was detected, since CPUEs and diver counts differed markedly (Fig. 4). CPUEs were high in May and June but remained low for the rest of the study period. The numbers of ruffe counted by scuba divers, however, increased until August and then decreased towards October. These marked differences were probably caused by an over-representation of ruffe in the gill nets during early summer, due to enhanced swimming activity during the spawning season.

Both species performed daily horizontal migrations (Fig. 5). During the day, either no or only a few fish were caught $($ Fig. $5 \mathrm{~b}, \mathrm{j}, \mathrm{n})$ or they were mainly caught in the deeper zone (except for perch in August at $\mathrm{S}_{\text {east }}$, Fig. 5f). Additionally, no fish was sighted by the scuba divers during the day (except for perch in August and October at $\left.S_{\text {east }}\right)$. During twilight, fish were caught in high abundances at both depths, and at night they were sighted by scuba divers.

In addition to the diurnal changes in depth distribution of perch, seasonal changes in their depth distribution were also apparent, independent of fish size (Fig. 5a-h). In May, perch were mainly caught at 10-m depth. During summer (June-August) perch increasingly used the shallow littoral zone (higher CPUEs at $2.5-\mathrm{m}$ depth) and, during August, some perch were even caught at $2.5-\mathrm{m}$ depth during the day at both sites. In September, the distribution of perch shifted again towards the deeper littoral zone. This seasonal pattern was observed through the gill net catches as well as the line transect-diving surveys. Ruffe, by contrast, did not show any seasonal changes in their daily migration pattern (Fig. 5i-p). During twilight, they were mainly caught at shallow depths, while during the night more ruffe were counted along the deeper transects at $S_{\text {east }}$ but not at $\mathrm{S}_{\mathrm{west}}$. 

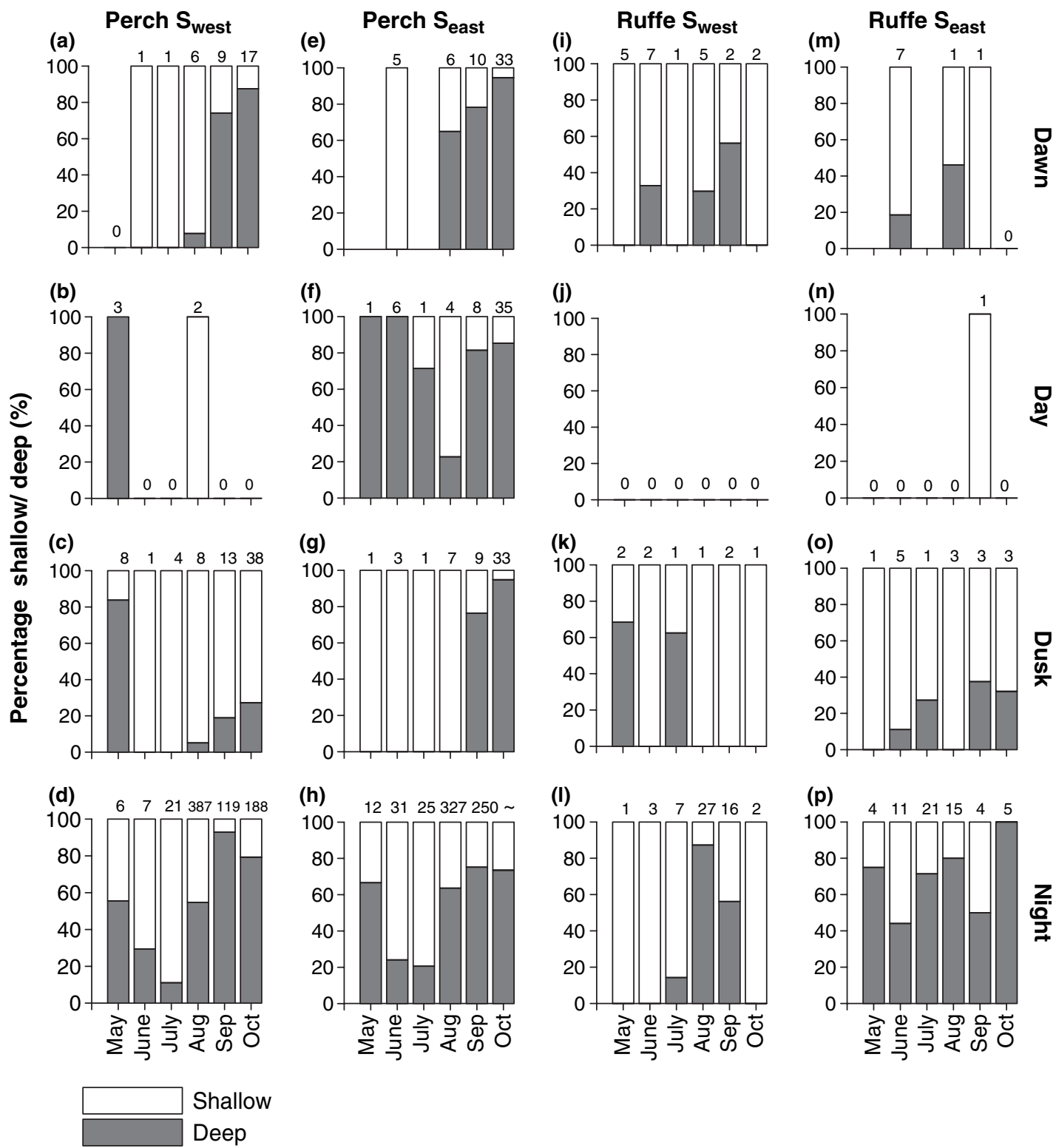

Fig. 5. Relative depth distribution at different times of the day for perch $(\mathrm{a}-\mathrm{h})$ and ruffe $(\mathrm{i}-\mathrm{p})$ at the two study sites in Lake Constance during 2004. For the dawn, day and dusk, CPUE data from bottom gill nets exposed at 2.5 - and $10-\mathrm{m}$ depths were used. For the night, scuba diver counts [averaged over the three transect lines ranging from 10- to $0.5-\mathrm{m}$ water depth and weighted by the number of transects in the shallow or deep area ( $\mathrm{N}$ fish $\left.\cdot 10 \mathrm{~m}^{-1}\right)$ ] were used. Numbers at the top of the bars indicate the sum of CPUE $\left(N \cdot 15 \mathrm{~m}^{-2} \cdot \mathrm{h}^{-1}\right)$ of the shallow and the deep net or the total number of fish counted along the rope ( $\simeq$ more than thousand). For $\mathrm{S}_{\text {east }}$, CPUE data are missing for the dawn sampling in May and July.

\section{Diet}

Perch and ruffe had contrasting feeding activities (Fig. 6). Perch fed during the day, as the proportions of medium-filled and full stomachs were the highest during the day and dusk (92/82\%). During the night, they ceased feeding and the relative number of perch with empty stomachs was the highest at dawn (62\%). Ruffe, by contrast, fed during the night, as $71 \%$ of the fish caught at dawn had full stomachs. This proportion decreased to $16 \%$ at dusk, while the number of ruffe with empty stomachs increased from $4 \%$ to $56 \%$.

The diet composition of perch varied strongly during the season (Table 1, Fig. 7). During the first half of the season (May-July) and in October, zooplankton was their main source of food, while in August zoobenthos and fish dominated in the diet of perch. In September, zoobenthos and zooplankton were of similar importance for small- and mediumsized perch (zoobenthos 54\% and zooplankton 46\%), while large perch remained piscivorous. The piscivory 


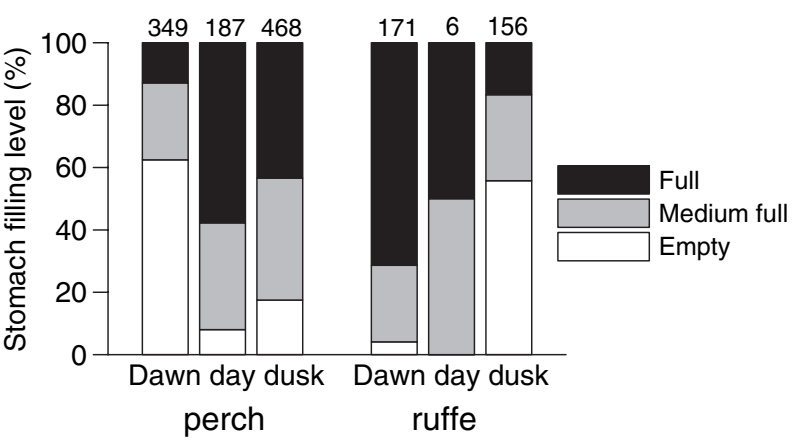

Fig. 6. Relative numbers of perch and ruffe with empty, medium filled or full stomachs. Numbers at the top of the bars indicate numbers of fish analysed. Data were pooled from May to October 2004.

Table 1. The main prey types of three size classes of perch on each sampling date.

\begin{tabular}{lllll}
\hline Year & Month & $\leq 9.5 \mathrm{~cm}$ & $9.5 \mathrm{~cm}<\mathrm{TL} \leq 13.0 \mathrm{~cm}$ & $>13 \mathrm{~cm}$ \\
\hline 2003 & August & Benthos & Fish & Fish \\
& October & Plankton & Plankton & Plankton \\
2004 & May & Plankton & Plankton & Plankton \\
& June & - & Plankton & Plankton \\
& July & - & Plankton & Plankton \\
& August & Benthos & Fish & Fish \\
& September & Benthos & Plankton & Fish \\
& October & Plankton & Plankton & Fish \\
2005 & September & Plankton & Plankton & Fish \\
2006 & June & Plankton & Plankton & Plankton \\
& August & Benthos & Benthos & Fish \\
\hline
\end{tabular}

A main prey type contributes more than $50 \%$ to the dry mass of the fish diet. Data were pooled over both study sites.

of the large perch and of some of the medium-sized perch by late July/early August coincided with the arrival of y-o-y perch in the littoral zone. The observed seasonal pattern in the diet of perch was not only found in 2004, but also in other years (Table 1). Ruffe fed nearly exclusively on zoobenthos throughout the entire study period.

The zooplankton ingested by perch strongly depended on the zooplankton community composition (Figs. 2 and 7). In May, when the zooplankton community was dominated by copepods, the diet of perch was also dominated by copepods. In June, when daphnids had their highest abundance, perch mainly fed on daphnids. The selectivity indices largely confirm the opportunistic zooplankton consumption by perch: at both sites the mean index values for the different zooplankton taxa were generally low (mostly $<0.25$ ) for all size classes of perch throughout the study period.

The benthic diet of perch included a wide range of organisms, but the most important prey organisms were gammarids (Fig. 7). In August 2003, G. roeseli contributed around $30 \%$ to the diet of $\mathrm{P}_{1}$. In August
2004 and 2006, however, G. roeseli was nearly entirely replaced by $D$. villosus, after the introduction of this pontocaspian gammarid into ULC and its rapid dispersal. Pupae of chironomids were the second most important benthic prey of perch. For ruffe, the most important prey organisms were chironomids, either larvae or pupae, followed by the mollusc Radix ovata and other insect larvae such as trichopterans and ephemeropterans (Fig. 7). Gammarids were only occasionally consumed in higher numbers.

The food choices of the two species resulted in medium or high interspecific diet overlap only in August and September (Table 2), when perch included benthic organisms in their diet. The only exceptions were medium index values in May at $\mathrm{S}_{\text {east }}$ for the diet overlap between medium-sized perch and both size classes of ruffe. Overall, the values for interspecific diet overlap between the different size classes of the two species reached above 0.25 in only $11 \%\left(\mathrm{~S}_{\mathrm{west}}\right)$ and $17 \%\left(\mathrm{~S}_{\text {east }}\right)$ of all cases. High diet overlap occurred predominantly between perch $<13.0 \mathrm{~cm}$ and ruffe, but as perch grew larger, and eventually became piscivorous, there was hardly any diet overlap between the species. Intraspecific diet overlap among size classes, however, was high throughout the year. The proportion of medium or high index values for intraspecific diet overlap in perch was $55 \%$ at $\mathrm{S}_{\text {west }}$ and $38 \%$ at $\mathrm{S}_{\text {east }}$ and occurred mainly in spring and autumn, when perch fed primarily on zooplankton, or in summer among $\mathrm{P}_{2}$ and $\mathrm{P}_{3}$, when both size classes fed on fish. For intraspecific diet overlap in ruffe, these proportions were even higher, $83 \%$ and $67 \%$, respectively.

Diet overlap was also high within both size classes of ruffe (Fig. 8). Medium index values predominated ( $71 \%$ and $66 \%$ of all comparisons), and individual feeding specialisations that would result in no diet overlap at all were very rare. Small perch showed a similar pattern to ruffe, with most diet overlaps being medium $(50 \%)$. However, $25 \%$ of the index values were zero, indicating individual feeding specialisations. In medium-sized perch, individual specialisations were even more apparent, resulting in high proportions of zero overlap (50\%). In this size class of perch, medium index values hardly occurred, but high index values accounted for $34 \%$ of all comparisons. In these cases, perch fed mainly on larger prey, such as gammarids, molluscs and fish, and index values indicated almost complete diet overlap (values $>0.8$ ). Averaged over all size classes of fish, perch consumed more prey items per fish than ruffe, as some perch fed heavily on small zooplankton organisms (up to 2500 organisms per fish). Generally, the bigger size classes within each species consumed less but heavier prey items. This was most pronounced in perch, who could feed on big prey organisms like fish or large gammarids due to their larger gape size. 

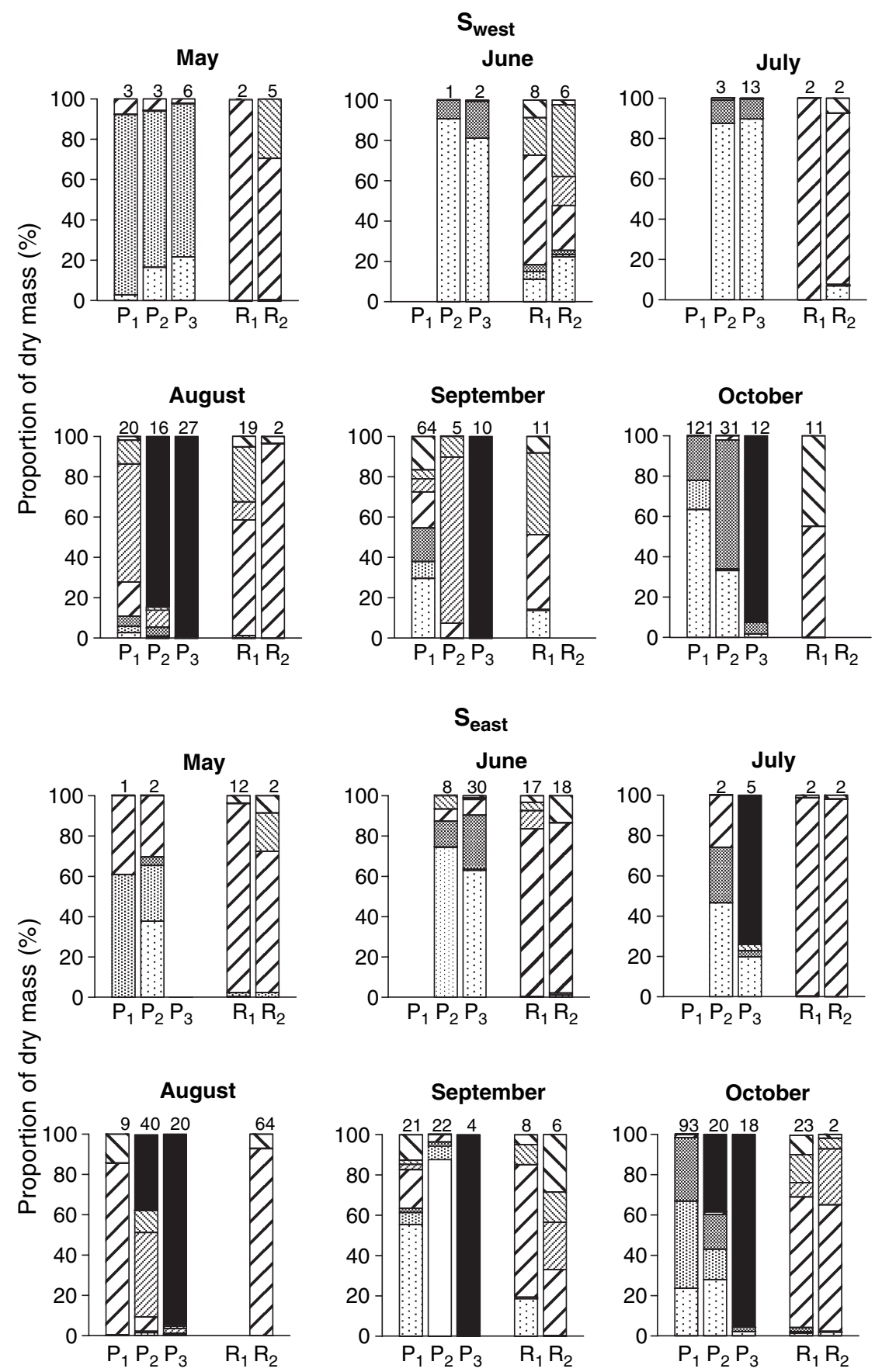

Fig. 7. Percentage stomach content composition on a dry mass basis for perch and ruffe from both study sites sampled from May to October 2004. Numbers at the top of bars indicate the numbers of fish stomachs analysed. $\mathrm{P}_{1}$ : perch $\leq 9.5 \mathrm{~cm}, \mathrm{P}_{2}$ : perch $9.5<\mathrm{TL} \leq 13.0 \mathrm{~cm}, \mathrm{P}_{3}$ : perch $>13 \mathrm{~cm}, \mathrm{R}_{1}$ : ruffe $\leq 9.0 \mathrm{~cm}, \mathrm{R}_{2}:$ ruffe $>9.0 \mathrm{~cm}$.

\section{Discussion}

Perch and ruffe exhibited clearly contrasting feeding strategies. Ruffe lived up to its reputation as a specialised benthos consumer (Ogle et al. 1995; Hölker \& Thiel 1998; Rezsu \& Specziar 2006) feeding mainly on chironomid larvae and pupae, irrespective of the sampling date. Perch, by contrast, had resumed its omnivorous feeding strategy in parallel to the ongoing reoligotrophication of ULC, feeding on zooplankton, zoobenthos and fish. In lakes of low productivity, where food resources are limited and may get exploited rapidly, a euryphagous species such as perch has the option to use alternative prey, whereas a food specialist such as ruffe has no choice but to react to the reduced food supply through slower growth and/or lower reproductive investment. Furthermore, intraspecific competition also increases with 
Table 2. Index values after Schoener (1971) for intra- and interspecific diet overlap among different size classes of perch and ruffe at both sampling sites based on 51 different prey types.

\begin{tabular}{|c|c|c|c|c|c|c|c|c|c|c|c|}
\hline \multirow[b]{2}{*}{ Year } & \multirow[b]{2}{*}{ Month } & \multicolumn{3}{|l|}{ Perch } & \multicolumn{6}{|c|}{ Perch-Ruffe } & \multirow{2}{*}{$\begin{array}{l}\text { Ruffe } \\
\mathrm{R}_{1}-\mathrm{R}_{2}\end{array}$} \\
\hline & & $P_{1}-P_{2}$ & $P_{1}-P_{3}$ & $P_{2}-P_{3}$ & $P_{1}-R_{1}$ & $\mathrm{P}_{2}-\mathrm{R}_{1}$ & $P_{3}-R_{1}$ & $P_{1}-R_{2}$ & $\mathrm{P}_{2}-\mathrm{R}_{2}$ & $\mathrm{P}_{3}-\mathrm{R}_{2}$ & \\
\hline \multicolumn{12}{|l|}{ Site $S_{\text {west }}$} \\
\hline \multirow[t]{2}{*}{2003} & August & 0.06 & 0.00 & 0.94 & 0.57 & 0.06 & 0.00 & & & & \\
\hline & October & 0.67 & 0.55 & 0.72 & 0.14 & 0.17 & 0.13 & 0.03 & 0.02 & 0.02 & 0.40 \\
\hline \multirow[t]{6}{*}{2004} & May & 0.81 & 0.66 & 0.82 & 0.08 & 0.06 & 0.02 & 0.08 & 0.06 & 0.03 & 0.51 \\
\hline & June & & & & & & 0.15 & & & 0.24 & 0.57 \\
\hline & July & & & 0.76 & & 0.01 & 0.00 & & 0.08 & 0.08 & 0.29 \\
\hline & August & 0.15 & 0.01 & 0.85 & 0.27 & 0.08 & 0.01 & 0.05 & 0.00 & 0.00 & 0.28 \\
\hline & September & 0.14 & 0.01 & 0.01 & 0.25 & 0.07 & 0.00 & & & & \\
\hline & October & 0.50 & 0.07 & 0.07 & 0.00 & 0.02 & 0.00 & & & & \\
\hline 2005 & September & 0.57 & & & 0.12 & 0.10 & & 0.11 & 0.37 & & 0.04 \\
\hline \multicolumn{12}{|l|}{ Site $S_{\text {East }}$} \\
\hline \multirow[t]{6}{*}{2004} & May & & & & & 0.33 & & & 0.30 & & 0.47 \\
\hline & June & & & 0.76 & & 0.05 & 0.07 & & 0.05 & 0.07 & 0.45 \\
\hline & July & & & & & & 0.01 & & & 0.00 & 0.06 \\
\hline & August & 0.07 & 0.01 & 0.42 & & & & 0.39 & 0.07 & 0.02 & \\
\hline & September & 0.59 & 0.00 & 0.00 & 0.33 & 0.22 & 0.00 & 0.14 & 0.01 & 0.00 & 0.29 \\
\hline & October & 0.53 & 0.04 & 0.43 & 0.06 & 0.06 & 0.03 & 0.04 & 0.04 & 0.02 & 0.42 \\
\hline 2005 & September & 0.24 & 0.00 & 0.00 & 0.11 & 0.12 & 0.00 & 0.05 & 0.55 & 0.00 & 0.17 \\
\hline
\end{tabular}

Bold: high overlap ( $\geq 0.5$ ); bold italicised: medium overlap $(0.25 \leq C<0.5)$; $P_{1}$ : perch $\leq 9.5 \mathrm{~cm} ; P_{2}$ : perch $9.5<T L \leq 13.0 \mathrm{~cm} ; P_{3}$ : perch $>13 \mathrm{~cm} ; R_{1}$ : ruffe $\leq 9.0 \mathrm{~cm}$; $\mathrm{R}_{2}$ : ruffe $>9.0 \mathrm{~cm}$.

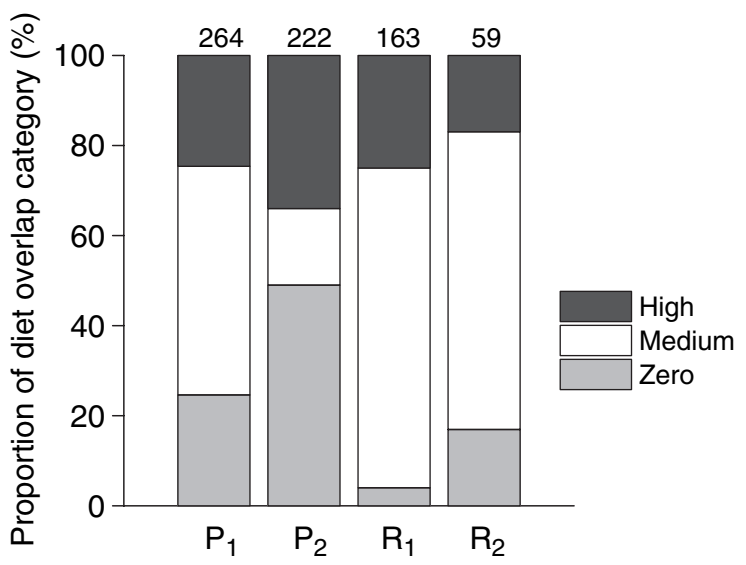

Fig. 8. Intraspecific diet overlap after Schoener (1971) among individuals, within one size class for perch and ruffe during August and September. Data were pooled over two study sites, years and months. Index values $<0.05$ are considered as zero, index values $0.05 \geq \mathrm{C}<0.5$ as intermedium and index values $\geq 0.5$ as high overlap. $\mathrm{P}_{1}$ : perch $\leq 9.5 \mathrm{~cm} ; \mathrm{P}_{2}$ : perch $9.5<\mathrm{TL} \leq 13.0 \mathrm{~cm} ; \mathrm{R}_{1}$ : ruffe $\leq 9.0 \mathrm{~cm} ; \mathrm{R}_{2}$ : ruffe $>9.0 \mathrm{~cm}$.

decreasing food availability. Ontogenetic diet shifts and individual feeding specialisations, however, which are both characteristic of the food generalist perch (Jamet \& Lair 1991; Hjelm et al. 2000; Radke \& Eckmann 2001; Rezsu \& Specziar 2006), can relieve intraspecific competition (Werner \& Gilliam 1984; Quevedo \& Olsson 2006). The specialised benthos consumer ruffe, however, is forced into severe intraspecific competition when the food base is reduced, as it does not perform pronounced ontogenetic diet shifts, nor does it show marked individual feeding specialisation. After a short plankton-feeding stage as larvae, they switch to zoobenthos already with $2-\mathrm{cm}$ body length, with chironimids being their preferred prey throughout their life (Hölker \& Thiel 1998; Rezsu \& Specziar 2006). In meso- or eutrophic systems, where the food base for benthivorous fish is better, this inflexibility is probably less detrimental, whereas in lakes of low productivity ruffe will probably be at a disadvantage.

Perch nowadays become cannibalistic in ULC at a length of $13 \mathrm{~cm}$ at the latest, yet 20 years ago all size classes of perch fed mainly on zooplankton (Becker 1988). This increased importance of cannibalism corresponds with the findings of Jeppesen et al. $(2000,2005)$ and Persson et al. (1991), who predicted a change from a planktivorous-dominated to a piscivorous-dominated fish community with decreasing lake productivity.

Consuming conspecifics can promote growth and reproduction in various ways because the nutritional requirements of the cannibalistic specimens are best met by conspecifics, as they supply all necessary compounds such as essential amino acids in optimal proportions (Meffe \& Crump 1987). Furthermore, with increasing body size, it becomes increasingly unprofitable for fish to cover their energy needs with small organisms such as zooplankton until the utilisation of this resource will finally not allow for a net increase in biomass (Mittelbach 1983; Diehl 1993). By becoming cannibalistic, however, the larger specimens can utilise these energetically unprofitable resources 
via their transformation by smaller conspecifics into larger, and biochemically more adequate, prey. Cannibals not only benefit from the energy gained by feeding on their conspecifics, but also from reducing competition for shared resources. The substantial impact of cannibalism on population dynamics was shown for perch in a long-term study by Persson et al. (2000).

The food choice of perch not only differed between size classes, but it also changed during the growth season in a typical pattern. In spring and early summer, perch consumed zooplankton, then switched to zoobenthos in August and consumed zooplankton again in October. Even the medium-sized and large fish, which became piscivorous in August, partly reverted to zooplanktivory in October. At least for the medium-sized fish it could be that the y-o-y outgrew their gape size. Hence, the ontogenetic diet shifts in perch are not as fixed as is often suggested (Jamet \& Lair 1991; Hjelm et al. 2000; Rezsu \& Specziar 2006); they are reversible, whereby perch can react very flexibly to a changing prey base. The notion that diet shifts are irreversible in perch may arise because field samples are often obtained only during summer, or because studies on food choice have mainly been carried out in lakes of high productivity, where a flexible reaction to changes in the prey base is not provoked (Radke \& Eckmann 2001).

The diet shift of perch in ULC from zooplanktivory to benthivory or piscivory in August may be caused either by low zooplankton abundance or by better availability of zoobenthos or fish. In August, total zooplankton abundances were indeed low in all study years, but they were even lower in July and October when perch did feed on zooplankton. Similarly, the shift to zoobenthos cannot be attributed to increased zoobenthos abundances, as they are generally the lowest in August in the littoral of ULC (Baumgärtner 2004; Scheifhacken 2006). Temperature-induced changes in the behaviour of benthic organisms, however, can enhance prey accessibility. Zoobenthos activity probably increases in August due to high water temperature, either through a direct effect on activity or through oxygen depletion in their refuges, forcing at least part of the macrozoobenthos community to abandon these refuges (Newell 1969; Winterbottom et al. 1997). During our study from 2003 to 2006, temperatures were always the highest in August, and as a consequence enhanced prey encounter rates may have triggered a diet shift in perch from zooplankton to zoobenthos. The diet shift of the larger perch to piscivory coincided with the arrival of y-o-y perch in the littoral zone, and with the daytime feeding activity of smaller benthivorous perch.

In contrast to small Swedish lakes where perch and ruffe use different habitats (Bergman 1988), both species used the same habitat in ULC, albeit with partly opposed activity patterns. During the day, both species were absent from the shallow littoral zone, but appeared there at dusk and disappeared at dawn. Ruffe arrived in the shallow littoral zone with empty stomachs to feed there during the night until their stomachs were well filled the next morning, whereas perch rested in the shallow littoral zone during the night (Imbrock et al. 1996). Perch fed almost exclusively during the day, which has been observed in other studies as well (Jamet \& Lair 1991; Beeck et al. 2002; Schleuter et al. 2007). As both species feed in the warm, shallow littoral zone during summer, the advantage ruffe may gain in the Swedish lakes by being a temperature generalist (Bergman 1987) is of minor importance in Lake Constance.

Despite this noticeable habitat overlap, competition for food between perch and ruffe was only marginal. Even during summer, when the smaller perch $(<13 \mathrm{~cm})$ were benthivorous, interspecific diet overlap reached only moderate values, indicating efficient food partitioning, which was also observed by Rezsu \& Specziar (2006). While gammarids contributed most to the diet of perch, ruffe fed predominantly on chironomids. Low interspecific diet overlap, however, can also result from niche divergence due to competition (Bonesi et al. 2004; D. Schleuter \& N. Scheifhacken, unpublished data). Bergman \& Greenberg (1994) demonstrated that an increased density of ruffe increased perch's consumption of zooplankton and of less preferred prey items. However, perch and ruffe prefer similar, but not completely identical benthic prey (Fullerton et al. 1998) and gammarids are known to be an important prey for perch (Cobb \& Watzin 1998; Rezsu \& Specziar 2006). Yet, when zooplankton abundances seriously declined in the 1990s, the high abundances of ruffe might have delayed a shift of perch to zoobenthos.

Intraspecific diet overlap between size classes was high for both species throughout the growing season. When perch fed on zoobenthos, intraspecific competition was probably relieved due to individual feeding specialisations. Some individuals consumed only one type of prey, and prey types often differed between individuals. This was most pronounced for larger perch, where $50 \%$ of all comparisons of individual stomach contents showed no diet overlap at all. Quevedo \& Olsson (2006) interpreted the high variability of isotopic composition of perch with a high specialisation in resource use, which they considered to be a strategy to reduce intraspecific competition. The long-term study of Svanbäck \& Persson (2004) confirm these results. They found that individual specialisation fluctuated with population density in response to changing resource levels. In ruffe, by contrast, diet variability between individuals 
was very low and individual diet overlap was mostly moderate to high.

The diel migrations of ruffe in ULC can be attributed to the differences in light intensity and food availability between the shallow littoral and greater depths. In the shallow littoral zone, water transparency is high and macrophyte stands that provide shelter from predators are sparse (Eckmann et al. 2006). Hence, predation risk is lower in the deeper, darker zones. The extremely light-sensitive eyes of ruffe may be an additional reason for them to avoid shallow waters during the day. Ruffe is able to feed at greater depth during the day due to its sensory abilities, but zoobenthos abundances decrease with depth in ULC, and they are already very low at around $10-\mathrm{m}$ depth (Mörtl 2003; Baumgärtner 2004). As a consequence, ruffe have to migrate into the shallow littoral zone at dusk to feed there until dawn. A similar migration pattern was described for adult ruffe in oligotrophic Lake Superior by Ogle et al. (1995). As prey capture rates of ruffe are low compared with those of perch (Bergman 1988; Becker 2000), the restriction of their feeding time to the night is considered as an additional disadvantage for ruffe in oligotrophic lakes, particularly during summer when nights are short. In more productive and hence more turbid systems, ruffe may feed continuously during the day and night (Hölker \& Temming 1996).

Perch also lived in the deeper littoral zone during the day which, in the case of the smaller fish, is probably a behavioural reaction to the lack of, or only sparsely developed, macrophyte cover in the littoral zone. In contrast to ruffe, however, perch mainly fed on zooplankton, which is also abundant at greater depths. During August, when smaller perch preyed primarily on zoobenthos, they also utilised the shallow littoral zone during the day.

The results of this study suggest that competition for food between perch and ruffe in a large oligotrophic lake is of minor importance. The direct consequences of reoligotrophication such as higher water transparency, a reduced food base and the higher prevalence of parasite infection in perch are therefore considered to be the main factors that control the growth and population dynamics of perch and ruffe (Eckmann et al. 2006). Perch reacted very flexibly to seasonal changes in food availability, and they alleviated intraspecific competition through individual feeding specialisations. These characteristics may allow them to maintain high population densities in spite of the generally lower food supply in lakes of low productivity. Ruffe, as a zoobenthos specialist, may not revert to other food resources when its food base decreases and intraspecific competition is intense due to weak individual feeding specialisations. And finally, ruffe do not become piscivorous as they grow larger, which is probably their most severe disadvantage in lakes of low productivity. With increasing intraspecific competition, ruffe is known for a trade-off between gonadal investment and somatic growth in terms of reducing fecundity and increasing size at maturation, which in turn will contribute to declining population densities (Devine et al. 2000). With ongoing reoligotrophication of ULC, intraspecific competition in ruffe is expected to become more intense, leading to further decreases in their population density, which will then translate into even weaker competition with perch.

\section{Acknowledgements}

We thank all our students and colleagues, especially Susanne Haertel-Borer and Arnd Weber for their assistance in the field. For the line transect scuba diving, we thank the scientific divers of the University of Konstanz. Special thanks are due to Myriam Schmid, for counting the plankton organisms and fish prey items. Christoph Berron, Marc Hamitou, Felix Heindl and Jens Hirzig also helped with stomach analyses. We thank three anonymous reviewers and an associate editor whose comments helped to improve the manuscript. Mary Morris corrected the English language. This study is embedded in the Collaborative Research Centre 454 'Littoral Zone of Lake Constance' financed by the German Science Foundation (DFG).

\section{References}

Baumgärtner, D. 2004. Principles of macroinvertebrate community structure in the littoral zone of Lake Constance. Dissertation. Konstanz: University of Konstanz. 197 pp.

Baumgärtner, D. \& Rothhaupt, K.-O. 2003. Predictive lengthdry mass regressions for freshwater invertebrates in a pre-alpine lake littoral. International Review of Hydrobiology 88: 453-463.

Becker, M. 1988. Freilandökologische Untersuchungen an planktivoren Fischen des Überlinger Sees mit Schwerpunkt einer differenzierten Nahrungsanalyse. Diploma Thesis. Konstanz: University of Konstanz. 122 pp.

Becker, A. 2000. Einfluss von Trübung auf das Fraßverhalten von Flussbarschen (Perca fluviatilis L.), Kaulbarschen (Gymnocephalus cernuus (L.)) und Dreistachligen Stichlingen (Gasterosteus aculeatus L.). Diploma Thesis. Konstanz: University of Konstanz. pp.

Beeck, P., Tauber, S., Kiel, S. \& Borcherding, J. 2002. 0+ Perch predation on $0+$ bream: a case study in a eutrophic gravel pit lake. Freshwater Biology 47: 2359-2369.

Bergman, E. 1987. Temperature-dependent differences in foraging ability of two percids, Perca fluviatilis and Gymnocephalus cernuus. Environmental Biology of Fishes 19: 45-53.

Bergman, E. 1988. Foraging abilities and niche breadth of two percids, Perca fluviatilis and Gymnocephalus cernua, under different environmental conditions. Journal of Animal Ecology 57: 443-453.

Bergman, E. 1991. Changes in abundance of two percids, Perca fluviatilis and Gymnocephalus cernuus, along a productivity gradient: relations to feeding strategies and competitive 
abilities. Canadian Journal of Fisheries \& Aquatic Sciences 48: 536-545.

Bergman, E. \& Greenberg, L.A. 1994. Competition between a planktivore, a benthivore, and a species with ontogenetic diet shifts. Ecology 75: 1233-1245.

Bonesi, L., Chanin, P. \& Macdonald, D.W. 2004. Competition between Eurasian otter Lutra lutra and American mink Mustela vison probed by niche shift. Oikos 106: 19-26.

Cobb, S.E. \& Watzin, M.C. 1998. Trophic interactions between yellow perch (Perca flavescens) and their benthic prey in a littoral zone community. Canadian Journal of Fisheries \& Aquatic Sciences 55: 28-36.

Collette, B.B., Ali, M.A., Hokanson, K.E.F., Nagiec, M., Thorpe, J.E., Weatherley, A.H. \& Willemsen, J. 1977. Biology of the percids. Journal of the Fisheries Research Board of Canada 34: 1890-1899.

Devine, J.A., Adams, C.E. \& Maitland, P.S. 2000. Changes in reproductive strategy in the ruffe during a period of establishment in a new habitat. Journal of Fish Biology 56: 1488-1496.

Diehl, S. 1988. Foraging efficiency of three freshwater fishes: effects of structural complexity and light. Oikos 53: 207-214.

Diehl, S. 1993. Effects of habitat structure on resource availability, diet and growth of benthivorous perch, Perca fluviatilis. Oikos 67: 403-414.

Dieterich, A., Baumgärtner, D. \& Eckmann, R. 2004. Competition for food between Eurasian perch (Perca fluviatilis L.) and ruffe (Gymnocephalus cernuus (L.)) over different substrate types. Ecology of Freshwater Fish 13: 236-244.

Eckmann, R. \& Rösch, R. 1998. Lake Constance fisheries and fish ecology. Archiv für Hydrobiologie-Advances in Limnology 53: 285-301.

Eckmann, R., Becker, M. \& Schmid, M. 2002. Estimating food consumption by a heavily fished stock of zooplanktivorous Coregonus lavaretus. Transactions of the American Fisheries Society 131: 946-955.

Eckmann, R., Gerster, S. \& Kraemer, A. 2006. Yields of European perch from Upper Lake Constance from 1910 to present. Fisheries Management \& Ecology 13: 381-390.

Fischer, P. \& Eckmann, R. 1997. Spatial distribution of littoral fish species in a large European lake, Lake Constance, Germany. Archiv für Hydrobiologie 140: 91-116.

Fullerton, A.H., Lamberti, G.A., Lodge, D.M. \& Berg, M.B. 1998. Prey preferences of Eurasian ruffe and yellow perch: comparison of laboratory results with composition of Great Lakes benthos. Journal of Great Lakes Research 24: 319-328.

Fullerton, A.H., Lamberti, G.A., Lodge, D.M. \& Goetz, F.W. 2000. Potential for resource competition between Eurasian ruffe and yellow perch: growth and RNA responses in laboratory experiments. Transactions of the American Fisheries Society 129: 1331-1339.

Hanson, P.C., Johnson, T.B., Schindler, D.E. \& Kitchell, J.F. 1997. Fish bioenergetics 3.0, Madison, WI: University of Wisconsin Sea Grant Institute.

Hartmann, J. 1975. Der Barsch (Perca fluviatilis) im eutrophierten Bodensee. Archiv für Hydrobiologie 76: 269-286.

Hartmann, J. \& Nümann, W. 1977. Percids of Lake Constance, a lake undergoing eutrophication. Journal of Fisheries Research Board of Canada 34: 1670-1677.
Hjelm, J., Persson, L. \& Christensen, B. 2000. Growth, morphological variation and ontogenetic niche shifts in perch (Perca fluviatilis) in relation to resource availability. Oecologia 122: 190-199.

Hölker, F. \& Temming, A. 1996. Gastric evacuation in ruffle (Gymnocephalus cernuus (L.)) and the estimation of food consumption from stomach content data of two $24 \mathrm{~h}$ fisheries in the Elbe Estuary. Archive of Fishery \& Marine Research 44: 47-67.

Hölker, F. \& Thiel, R. 1998. Biology of ruffe (Gymnocephalus cernuus (L.)). A review of selected aspects from European literature. Journal of Great Lakes Research 24: 186-204.

Imbrock, F., Appenzeller, A. \& Eckmann, R. 1996. Diel and seasonal distribution of perch in Lake Constance: a hydroacoustic study and in situ observations. Journal of Fish Biology 49: 1-13.

Jamet, J.L. \& Lair, N. 1991. An example of diel feeding cycle of two percids, perch (Perca fluviatilis) and ruffe (Gymnocephalus cernuus) in eutrophic Lake Aydat (France). Annales des Sciences Naturelles Zoologie et Biologie Animale 12: 99-105.

Janssen, J. 1997. Comparison of response distance to prey via the lateral line in the ruffe and yellow perch. Journal of Fish Biology 51: 921-930.

Jeppesen, E., Jensen Jens, P., Sondergaard, M., Lauridsen, T. \& Landkildehus, F. 2000. Trophic structure, species richness and biodiversity in Danish lakes: changes along a phosphorus gradient. Freshwater Biology 45: 201-218.

Jeppesen, E., Sondergaard, M., Jensen, J.P., Havens, K.E., Anneville, O., Carvalho, L., Coveney, M.F., Deneke, R., Dokulil, M.T., Foy, B., Gerdeaux, D., Hampton, S.E., Hilt, S., Kangur, K., Koehler, J., Lammens, E.H.H.R., Lauridsen, T.L., Manca, M., Miracle, M.R., Moss, B., Noges, P., Persson, G., Phillips, G., Portielje, R., Schelske, C.L., Straile, D., Tatrai, I., Willen, E. \& Winder, M. 2005. Lake responses to reduced nutrient loading - an analysis of contemporary long-term data from 35 case studies. Freshwater Biology 50: 1747-1771.

Laude, U. 2002. Verteilung und Ernährung larvaler und juveniler Stadien von Plötze (Rutilus rutilus (L.)) und Barsch (Perca fluviatilis L.) im Biomanipulations experiment Feldberger Haussee (Mecklenburg-Vorpommern). Dissertation. Dresden: TU-Dresden. 162 pp.

Meffe, G.K. \& Crump, M.L. 1987. Possible growth and reproductive benefits of cannibalism in the mosquitofish. American Naturalist 129: 203-212.

Mittelbach, G.G. 1983. Optimal foraging in bluegills. Oecologia 59: 157-162.

Mörtl, M. 2003. Biotic interactions in the infralittoral of Lake Constance. Dissertation. Konstanz: University of Konstanz. $158 \mathrm{pp}$.

Newell, R.C. 1969. Effect of fluctuations in temperature on the metabolism of intertidal invertebrates. American Zoologist 9: 293-307.

Nümann, W. 1939. Untersuchung über die Biologie einiger Bodenseefische in der Uferregion und den Randgebieten des freien Sees. Zeitschrift für Fischerei 37: 637-688.

Ogle, D.H., Selgeby, J.H., Newman, R.M. \& Henry, M.G. 1995. Diet and feeding periodicity of ruffe in the St. Louis River Estuary, Lake Superior. Transactions of the American Fisheries Society 124: 356-369. 
Olin, M., Rask, M., Ruuhijarvi, J., Kurkilahti, M., Ala-Opas, P. \& Ylonen, O. 2002. Fish community structure in mesotrophic and eutrophic lakes of southern Finland: the relative abundances of percids and cyprinids along a trophic gradient. Journal of Fish Biology 60: 593-612.

Persson, L., Diehl, S., Johansson, L., Andersson, G. \& Hamrin, S.F. 1991. Shifts in fish communities along the productivity gradient of temperate lakes patterns and the importance of sizestructured interactions. Journal of Fish Biology 38: 281-294.

Persson, L., Bystrom, P. \& Wahlstrom, E. 2000. Cannibalism and competition in Eurasian perch: population dynamics of an ontogenetic omnivore. Ecology 81: 1058-1071.

Quevedo, M. \& Olsson, J. 2006. The effect of small-scale resource origin on trophic position estimates in Perca fluviatilis. Journal of Fish Biology 69: 141-150.

Radke, R.J. \& Eckmann, R. 2001. No general percid dominance under mesotrophic lake conditions: a test of several hypotheses. Limnologica 31: 37-44.

Radke, R.J. \& Gaupisch, A. 2005. Effects of phytoplanktoninduced turbidity on predation success of piscivorous Eurasian perch (Perca fluviatilis): possible implications for fish community structure in lakes. Naturwissenschaften 92: 91-94.

Reyjol, Y., Fischer, P., Lek, S., Rösch, R. \& Eckmann, R. 2005. Studying the spatiotemporal variation of the littoral fish community in a large prealpine lake, using self-organizing mapping. Canadian Journal of Fisheries \& Aquatic Sciences 62: 2294-2302.

Rezsu, E. \& Specziar, A. 2006. Ontogenetic diet profiles and size-dependent diet partitioning of ruffe Gymnocephalus cernuus, perch Perca fluviatilis and pumpkinseed Lepomis gibbosus in Lake Balaton. Ecology of Freshwater Fish 15: 339-349.

Rösch, R. \& Schmid, W. 1996. Ruffe (Gymnocephalus cernuus L.), newly introduced into Lake Constance: preliminary data on population biology and possible effects on whitefish (Coregonus lavaretus L.). Annales Zoologici Fennici 33: 467-471.

Scheifhacken, N. 2006. Life at turbulent sites: benthic communities in lake littorals interacting with abiotic and biotic constraints. Field and mesocosm investigations. Dissertation. Konstanz: University of Konstanz. 197 pp.

Schleuter, D. \& Eckmann, R. 2006. Competition between perch and ruffe: the advantage of turning night into day. Freshwater Biology 51: 287-297.

Schleuter, D., Haertel-Borer, S.S., Fischer, P. \& Eckmann, R. 2007. Respiration rates of Eurasian perch (Percafluviatilis) and ruffe: lower energy costs in groups. Transactions of the American Fisheries Society 136: 43-55.

Schmid, W. 1999. Zur Biologie des Kaulbarsches (Gymnocephalus cernuus (L.)) im Bodensee: "Ein Neozoon im Ökosystem". Dissertation. Konstanz: University of Konstanz. 91 pp.

Schoener, T.W. 1971. Theory of feeding strategies. Annual Review of Ecology and Systematics 2: 369-404.

Strauss, R.E. 1979. Reliability estimates for Ivlev's electivity index, the forage ratio, and a proposed linear index of food selection. Transactions of the American Fisheries Society 108: 344-352.

Svanbäck, R. \& Persson, L. 2004. Individual diet specialization, niche width and population dynamics: implications for trophic polymorphisms. Journal of Animal Ecology 73: 973-982.

Werner, E.E. \& Gilliam, J.F. 1984. The ontogenetic niche and species interactions in size-structured populations. Annual Review of Ecology and Systematics 15: 393-425.

Winterbottom, J.H., Orton, S.E. \& Hildrew, A.G. 1997. Field experiments on the mobility of benthic invertebrates in a southern English stream. Freshwater Biology 38: $37-47$. 